\title{
A Study of the Major Graph Labelings of Trees
}

\author{
Auparajita KRISHNAA \\ Guest Faculty, B-1, 101 Vaishali Apartments \\ Sector 4, Hiranmagri, Udaipur 313002 India \\ e-mail: godseeking1@yahoo.com
}

Received: October 2004

\begin{abstract}
Tree is one of the most studied and practically useful classes of graphs and is the attention of a great number of studies. There is absence of generalized results for tree as a class and even for one kind of labeling as whole. Only specialized results exist limited to specific types of trees only. A number of conjectures stand being unsolved. Graham and Sloane (1980) conjectured trees to be Harmonious and Ringel-Kotzig conjectured trees to be Graceful about three decades ago. Kotzig and Rosa (1970) ask the question whether all trees are Magic or not. No generalized result for Antimagic labeling is given for trees so far. This paper presents the methodologies to obtain the major labeling schemes for trees viz., Harmonious, Sequential, Felicitous, Graceful, Antimagic and found the trees to be not Magic except $T(2,1)$, thus solving the said conjectures. These findings could also be useful for those working in fields where graphs serve as models.
\end{abstract}

Key words: vertex labeling, edge labeling.

\section{Introduction}

Trees have been worked on mostly for Graceful and Harmonious labelings as discussed in Gallian (1998). The results obtained are often for special classes of trees and are thus limited and not generalized. Among the trees known to be Graceful are caterpillars given by Rosa (1967). Trees with at most 4 end vertices have been shown to be Graceful by Huang, Kotzig and Rosa (1982) and Jin, Meng and Wang (1993). Aldred and McKay (1992) have shown Gracefulness of trees with at most 27 vertices. Caterpillars are shown to be Sequential by Grace (1983) and Felicitous by Shee and Lee (1989). Aldred and McKay (1992) used a computer to show that all trees with at most 26 vertices are Harmonious. Whereas, Krishnaa (2001) has given a generalized computerized solution and algorithms for the major graph labeling schemes for smaller graphs. This comprehensive solution checks the existence of any of the major labeling schemes namely Harmonious, Felicitous, Sequential, Graceful. Magic and Antimagic labeling schemes, for an arbitrary graph, producing great number of labellings when they exist. Graham and Sloane (1980) showed caterpillars to be Harmonious. Bermond (1979) conjectured that lobsters (tree with the property that the removal of the endpoints leaves a caterpillar) and a number of authors have worked on special cases of this including Ng (1986) among others. Gallian (1998) has suggested for lobsters to be studied for being Harmonious as well. More specialized results of trees are contained in (Bermond, 1979; Cahit, 1989; Bloom, 1979; 
Koh et al., 1979) among others. Therefore, the results are not at all generalized and so restricted often to just one kind of tree and they render inapplicable for another type of tree. Graham and Sloane (1980) conjectured that trees are Harmonious and RingelKotzig conjectured trees to be graceful. Assessing the results obtained so far Gallian (1998) states “... sweeping conjectures are probably true but appear hopelessly difficult to prove". This work provides generalized solutions to all the fundamental vertex and edge labeling schemes for the trees with the methodologies and results presented in the following sections.

\section{Main Results about the Development of Algorithms with Respect to Labelings of Trees}

First let us consider the vertex labelings for a graph $G(p, q)$ with $p$ vertices and $q$ edges.

A Harmonious labeling is a function $f: V(G) \rightarrow Z_{q}=\{0,1,2, \ldots,(q-1)\}$; so that the induced edge label is given by $(f(x)+f(y))(\bmod q)$, repetition of one vertex label is allowed for trees. Whereas a Felicitous labeling is given by $f: V(G) \rightarrow Z_{q}=$ $\{0,1,2, \ldots, q\}$; so that the induced edge label is given by $(f(x)+f(y))(\bmod q)$. The Sequential labeling is given by $f: V(G) \rightarrow Z_{q}=\{0,1,2, \ldots,(q-1)\}$; the induced edge label is given by $(f(x)+f(y))$. Edge labels are $\{k, k+1, k+2, \ldots, k+q-1\}$ where $k$ is integer. Graceful labeling is given by $f: V(G) \rightarrow Z_{q}=\{0,1,2, \ldots, q\}$; the induced edge label is given by $|f(x)-f(y)|$. Edge labelings comprise of assigning labels to the edges. A graph is said to have Magic labeling if the $q$ edges can be labeled by using all the numbers $1,2,3, \ldots, q$ such that the sum of the edge labels of the incident edges of all the vertices is the same. A graph has Antimagic labeling if the edges are labeled with $1,2,3, \ldots, q$ such that the sums of the incident edge labels for all the vertices are distinct.

\subsection{Algorithms for the Vertex Labelings}

Consider a tree $T(p, q)$ with $p$ vertices and $q$ edges.

Algorithm HS for Harmonious and Sequential Labelings of a Tree

1. Draw the tree as a bipartite graph in two partite sets denoted as Left $(L)$ and Right $(R)$. Let the number of vertices in $L$ be $x$.

2. Number the vertices in $L$ starting from top going to bottom consecutively as $0,1, \ldots,(x-1)$.

3. Number the vertices in $R$ starting from top going to bottom consecutively as ( $x-$ $1), x,(x+1), \ldots,(q-1)$. Note that these numbers are the vertex labels.

4. Compute the edge labels by adding them modulo $q$ for Harmonious and simple addition for Sequential.

5. The resulting labeling is Harmonious and Sequential.

Various kinds of trees with several combinations of even, odd edges and vertices in bipartite sets have been selected for the labelings and shown in the figures. Harmonious and Sequential trees obtained using the Algorithm HS are shown in Fig. 1. 

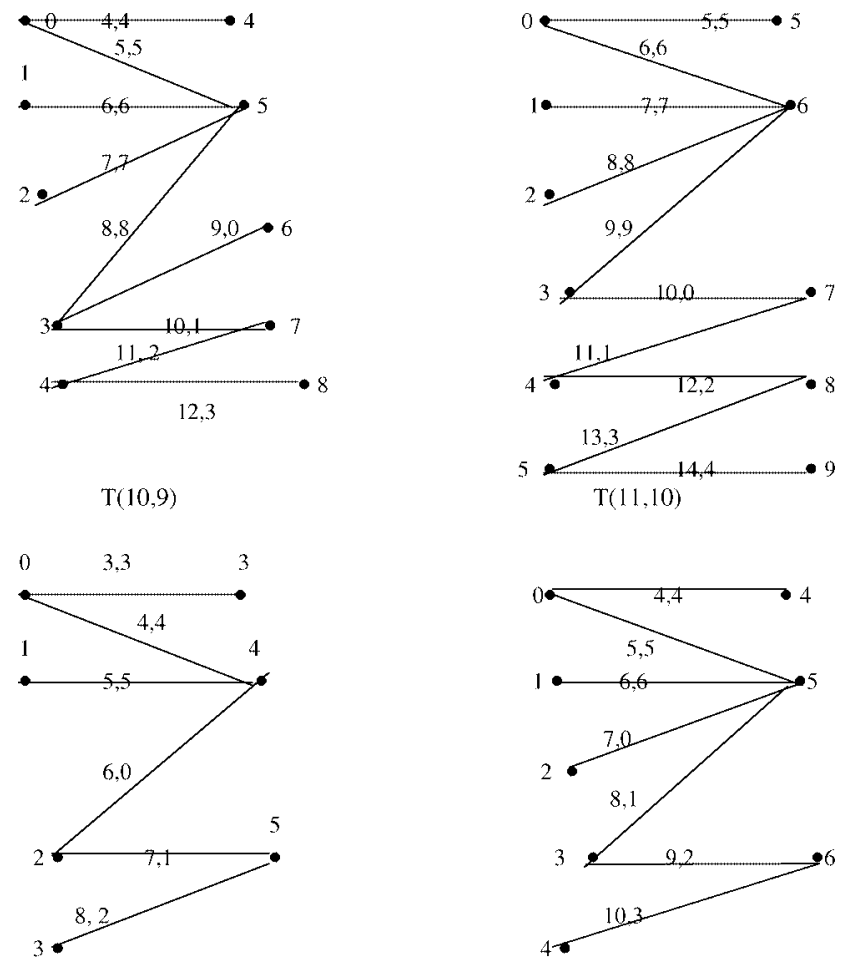

$\mathrm{T}(7,6)$

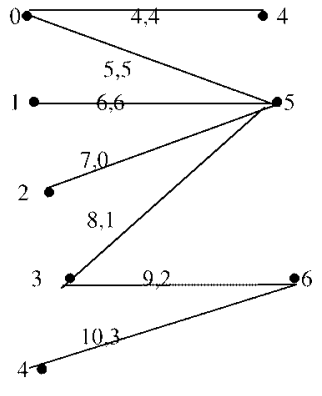

$\mathrm{T}(8,7)$

Fig. 1. Sequential and Harmonious Trees; Sequential and Harmonious edge labels written on the edges on left and right respectively separated by a comma.

Algorithm FS for Felicitous and Sequential Labeling of a Tree

1. Draw the tree as a bipartite graph in two partite sets denoted as Left $(L)$ and Right $(R)$. Let the number of vertices in $L$ be $x$.

2. Number the vertices in $L$ starting from top going to bottom consecutively as $0,1, \ldots,(x-1)$.

3. Number the vertices in $R$ starting from top going to bottom consecutively as $x,(x+$ $1),(x+2), \ldots, q$. Note that these numbers are the vertex labels.

4. Compute the edge labels by adding them modulo $q$.

5. The resulting labeling is Felicitous and Sequential.

A Harmonious labeling is Felicitous also but a Felicitous labeling involving the vertex label ' $q$ ' is not Harmonious. The Algorithm FS includes ' $q$ ' as a vertex label and results in a characteristic Felicitous labeling which is not Harmonious. Fig. 2 shows the Felicitous and Sequential trees obtained using this algorithm. Note that this labeling gives the Sequential labeling also with one higher in the edge labels as compared to the Sequential trees obtained using Algorithm HS. The Felicitous edge labels $\{0,1,2, \ldots, q-1\}$ also start one higher from top down as compared to the Harmonious edges. Felicitous and Sequential trees obtained using the Algorithm FS are shown in Fig. 2. 


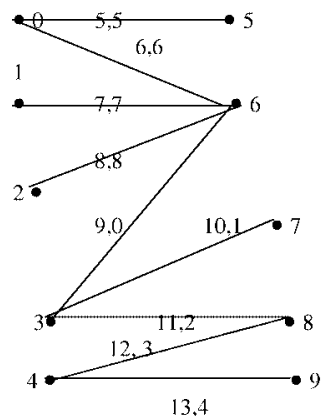

13,4

$\mathrm{T}(10,9)$

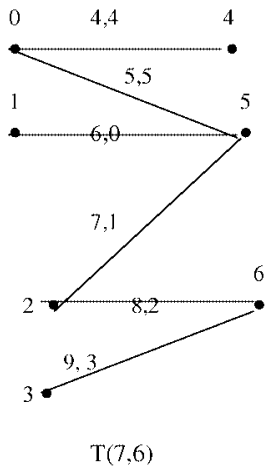

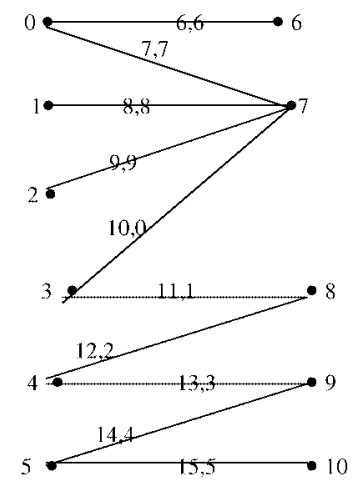

$\mathrm{T}(11,10)$

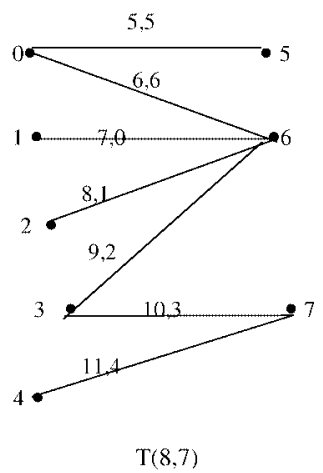

Fig. 2. Sequential and Felicitous Trees; Sequential and Felicitous edge labels written on the edges on left and right respectively separated by a comma.

\section{Algorithm G for Graceful Labeling of a Tree}

1. Draw the tree as a bipartite graph in two partite sets denoted as Left $(L)$ and Right $(R)$. Let the number of vertices in $L$ be $x$.

2. Number the vertices in $L$ starting from top going to bottom consecutively as $0,1, \ldots,(x-1)$.

3. Number the vertices in $R$ starting from bottom going to top consecutively as $x,(x+$ $1),(x+2), \ldots, q$. Note that these numbers are the vertex labels.

4. Compute the edge labels by taking the absolute value of the difference of the incident vertex labels.

5. The resulting labeling is Graceful.

Fig. 3 shows the Graceful trees obtained using Algorithm G. 


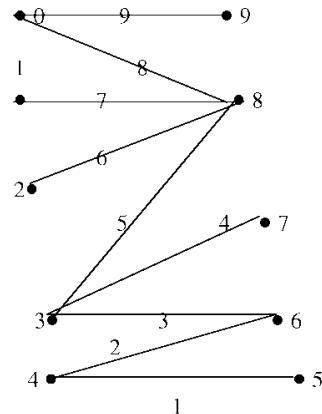

$\mathrm{T}(10,9)$

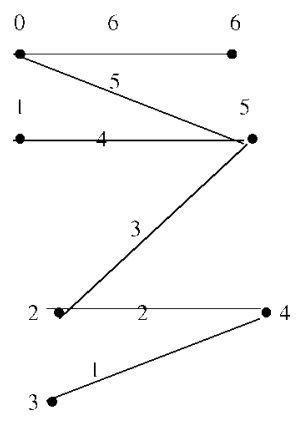

$\mathrm{T}(7,6)$
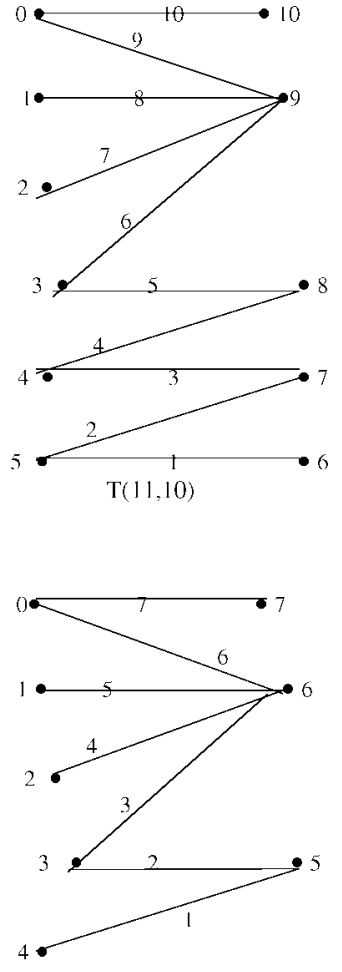

$\mathrm{T}(8.7)$

Fig. 3. Graceful Trees.

\subsection{Algorithm for Edge Labelings}

The Antimagic labeling behaves totally differently and is less structured than the vertex labelings hence the algorithm has to be flexible to handle that. The following algorithm gives the Antimagic labeling for a tree.

Algorithm AM for Antimagic Labeling of a Tree

1. Draw the tree as a bipartite graph.

2. Number the edges corresponding to the end-vertices with $1,2,3, \ldots, x$ from top down.

3. Then number the other edges as $(x+1),(x+2), \ldots, q$ going from either top down or bottom up. Some trees give Antimagic labeling with top down whereas some give bottom up.

4. If two vertex labels turn out to be the same then interchange the adjacent edge labels for the repeated vertex labels to be different. The edge labelings on edges corresponding to end-vertices should not be changed since they act independently.

The tree $T(7,6)$ in Fig. 4 demonstrates this case.

Certain trees give an Antimagic labeling when Step 3 is done from top to bottom and 

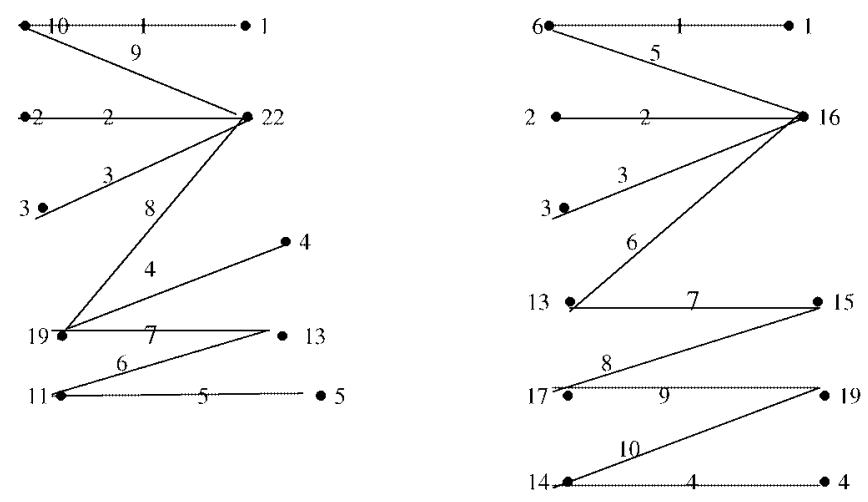

$\mathrm{T}(10,9)$

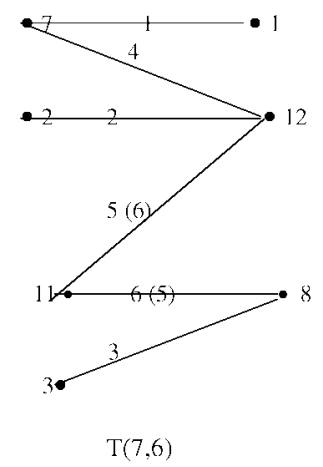

$\mathrm{T}(11,10)$

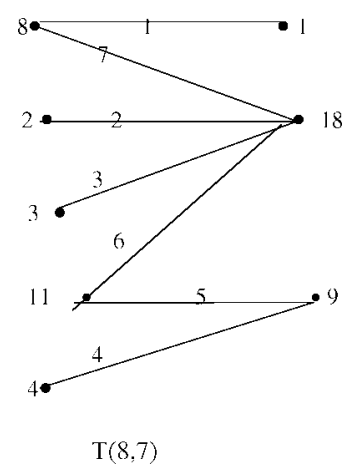

Fig. 4. Antimagic Trees; the edge labels in parentheses for $T(7,6)$ show the interchanged edge labels as in Step 4 of the Algorithm AM.

others when for bottom to top. Fig. 4 shows the Antimagic Trees.

Another property of a tree is given in the following theorem in Chartrand and Lesniak (1986).

Theorem 1. A tree has at least 2 end vertices.

MAGIC LABELING: Edges are numbered uniquely from $\{1,2, \ldots, q\}$ as per the norm of labeling the edges in edge labeling. Since a tree has at least 2 end vertices (Theorem 1) thus the induced vertex labels of these end vertices will never be the same. Therefore a tree can not have a Magic labeling except when tree is $T(2,1)$.

Following figures show trees $T(p, q)$ with various labelings obtained according to the algorithms.

\subsection{Logic of the Algorithms}

The Tree has very definite properties for its structure the significance of which has not been understood in its entirety so far. When designing the algorithms and devising the 


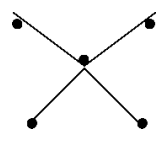

Fig. 5 (a). Star.

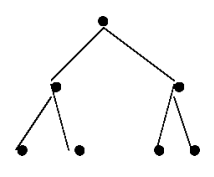

Fig. 6 (a). Binary Tree.

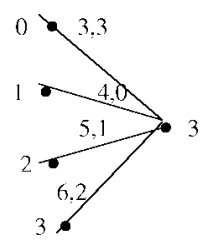

Fig. 5 (b). Star redrawn as bipartite graph; Harmonious and Sequential labelings shown.

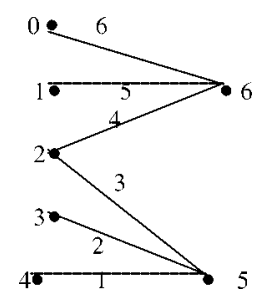

Fig. 6 (b). Binary Tree redrawn as bipartite graph shown with Graceful labeling.

scheme for assignment of vertex or edge labels, structure of the graph is the deciding factor. These properties of tree have been capitalized here to develop the algorithms given in Section 2.1 and 2.2. Let us look at certain characterizations about trees as per Chartrand and Lesniak (1986):

Theorem 2. Graph $G(p, q)$ is a tree if and only if it is acyclic (without cycles) and $q=$ $p-1$.

Theorem 3. Graph $G(p, q)$ is a tree if and only if $G$ is connected and $q=p-1$.

Theorem 4. Graph $G(p, q)$ is a tree if and only if every two distinct vertices of $G$ are connected by a unique path of $G$.

These facts are elaborated as follows:

(1) Any tree can be drawn as a bipartite graph (Theorem 2) with edges only between the vertices in $L$ and $R$.

(2) Trees are without cycles and have only one edge between any two vertices in the partite sets $L$ and $R$ (Theorem 4 implies that any two vertices have only one path or an edge).

(3) Vertex label from the set $\{0,1,2, \ldots,(q-1)\}$ are assigned uniquely as given in the algorithms. (In case of Harmonious and Sequential exactly 1 vertex label is repeated as per definition). In Felicitous and Graceful also similar process is done with the set $\{0,1,2, \ldots, q\}$ without repeating any vertex label.

(4) The connected, acyclic tree with the $p$ vertices and $(p-1)$ edges which is neither in excess nor less but just the right number of vertices and edges plays an important role. Drawing the tree as bipartite graph results in arriving at the scheme of 
assignment of the vertex labels. Therefore while computing the edge labels top down (bottom up), there is difference of exactly 1 in the magnitude of one vertex label. Hence the corresponding edge labels also differ by exactly 1 in magnitude top down (bottom up). Therefore the edge labels are distinct, consecutive and form the $\operatorname{set}\{0,1, \ldots, q-1\},\{1,2, \ldots, q\}$ or $\{k, k+1, \ldots, k+q-1\}$ depending on the operation.

For example, consider the trees $T(3,2)$ and $T(4,3)$ draws as bipartite graphs with even and odd edges respectively and vertices labeled according to Algorithm HS.
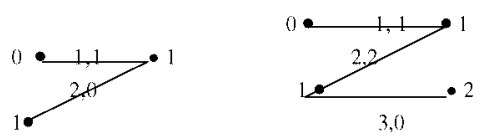

While adding the vertex labels in case of add $\bmod 2$, the edge labels will be 0,1 and add $\bmod 3$, edge labels will be $0,1,2$.

(6) Note that, in Harmonious and Sequential labelings, the vertex labels in the partite set $L$ from the top down is $0,1,2, \ldots,\lfloor q / 2\rfloor$ whereas in the partite set $R$, the vertex labels from top down is $\lfloor q / 2\rfloor,\lfloor q / 2\rfloor+1, \ldots, q-1$. In Harmonious, edge labels starting from $\lfloor q / 2\rfloor$ upto $(q-1)$ are obtained top down as these are added to 0 to get back the number itself. Then a 0 is obtained and thereafter the numbers $1,2, \ldots,\lfloor q / 2\rfloor-1$ are obtained. In Felicitous, $\lfloor q / 2\rfloor$ appears only once and in $L$. Therefore the set $\{0,1,2, \ldots, q-1\}$ is obtained.

In Graceful, the vertex labels in the partite set $L$ from the top down are $0,1,2, \ldots,\lfloor q / 2\rfloor$ whereas in the partite set $R$, the vertex labels from bottom up are $\lfloor q / 2\rfloor+1,\lfloor q / 2\rfloor+2, \ldots, q$. Therefore, taking the absolute value of the differences of these vertex labels from bottom up will give $1,2, \ldots, q$. Note that going bottom up, the difference between successive pairs of vertex labels, there is difference of exactly 1 in magnitude of a vertex label therefore resulting edge labels also have the same difference. Result is the edge labels being the set $\{1,2, \ldots, q\}$.

\section{Conclusion}

Since labeled graphs serve as practically useful models for wide ranging applications such as communications network, circuit design, coding theory, radar, astronomy, X-ray crystallography, it is desired to have generalized results or results for a whole class if possible. But trying to reach such a solution, it frequently ends up in creating more subclasses and finding solutions for them yielding specialized results only. This work has presented the generalized solutions to obtain the major labeling schemes for trees viz., Harmonious, Sequential, Felicitous, Graceful, Antimagic and found the trees to be not Magic except T(2,1), thus solving the conjectures of Ringel-Kotzig - trees are Graceful, Graham and Sloane (1980) - trees are Harmonious, Kotzig and Rosa (1970) - whether all trees are Magic or not. In labeling of the trees, the properties of its structure namely 
the $p$ vertices and $(p-1)$ edges, connectivity and acyclic have plus the crucial redrawing the tree as a bipartite graph led to the solutions. The resulting algorithms are not difficult to work with either.

\section{References}

Aldred, R.E.L., and B.D. McKay (1992). Graceful and Harmonious Labellings of Trees. Preprint.

Bermond, J.C. (1979). Graceful Graphs, Radio Antennae and French Windmills, Graph Theory and Combinatorics. Pitman, London.

Bloom, G.S. (1979). A chronology of the Ringel-Kotzig conjecture and the continuing quest to call all trees Graceful. Ann. N.Y. Sci., 326, 53-65.

Cahit, I. (1989). Status of graceful tree conjecture in 1989. In R. Bodendiek and R. Henn (Eds.), Topics in Combinatorics and Graph Theory. Physica-Verlag, Heidelberg.

Gallian, J.A. (1998). A dynamic survey of graph labeling. The Electronic Journal of Combinatorics.

Grace, T. (1983). On sequential labelings of graphs. J. Graph Theory, 7, 195-201.

Graham, R.L., and N.J.A. Sloane (1980). On additive bases and harmonious graphs. SIAM J. Algebraic Discrete Methods, 1, 382-404.

Huang, C., A. Kotzig and A. Rosa (1982). Further results on tree labellings. Utilitas Math., 21C, 31-48.

Jin, D.J., F.H. Meng and J.G. Wang (1992). The gracefulness of trees with diameter 4. Acta Sci. Natur. Univ. Jilin, 17-22.

Kotzig, A., and A. Rosa (1970). Magic Valuations of Complete Graphs. Centre de Recherches Mathematiques, Universite de Montreal, CRM-175.

Koh, K.M., D.G. Rogers and T. Tan (1979). A graceful arboretum: a survey of graceful trees. In Proceedings of Franco-Southeast Asian Conf., Singapore. pp. 278-287.

Krishnaa, A. (2001). Computer modelling of graph labelings. In Proceedings of National Conference on Mathematical and Computational Models, Coimbatore, India. pp. 293-301.

Krishnaa A., M.S. Dulawat and G.S. Rathore (2004). A study on statistical analysis of antimagic graph labellings. J. of Rajasthan Academy of Physical Sciences, 3(2), 111-120.

$\mathrm{Ng}$, H.K. (1986). Gracefulness of a class of lobsters. Notices AMS, 7, 825-05-294.

Ringel, G., A. Llado and O. Serra (1996). Another tree conjecture. Bull. Inst. Combin. Appl., 18, 83-85.

Rosa, A. (1967). On certain valuations of the vertices of a graph. In Theory of Graphs (Internat. Symposium, Rome, July 1966). Gordon and Breach, N.Y. and Dunod Paris. pp. 349-355.

Shee, S., and S. Lee (1989). On Harmonious and Felicitous labeling of graphs. Congress Numer., 68, $155-170$.

A. Krishnaa holds masters in computer application and masters in mathematical sciences (USA) and did her PhD in computer modelling in graph theory. She has several research papers to her credit. She is teaching mathematics in the university.

Her research interests include computer application in mathematics and statistics, graph theory, algorithms. 


\section{Pagrindiniu grafu žymėjimu medžiams tyrimas}

\section{Auparajita KRISHNAA}

Medis yra viena iš labiausiai ištirtų ir praktiškai naudingu grafu klasių. Tačiau nèra apibendrintu netgi vieno tipo žymejjimo rezultatu šiai klasei, tèra tik specifiniams medžiu tipams specializuoti rezultatai. Šiame straipsnyje yra pristatoma metodologija, skirta pagrindiniu žymèjimo schemų medžiams nustatymui, nustatytas medžių tipas pagal žymėjimus. Gauti rezultatai gali būti naudingi tyrimams, kuriuose grafai naudojami kaip modeliai. 